\title{
GESTÃO ESCOLAR E PERTENÇA PROFISSIONAL: UMA ANÁLISE DOS DISCURSOS DE PROFESSORAS INICIANTES
}

\author{
SCHOOL MANAGEMENT AND PROFESSIONAL MEMBERSHIP: AN ANALYSIS OF INITIATING TEACHER \\ SPEECHES \\ GESTIÓN ESCOLAR Y PERTENENCIA PROFESIONAL: UN ANÁLISIS DE LOS DISCURSOS DE PROFESORES \\ INICIANTES
}

\author{
RODRIGUES, Isabel Daiane Weber Machry ${ }^{1}$ \\ FERREIRA, Liliana Soares ${ }^{2}$
}

\begin{abstract}
RESUMO
Sistematiza-se a análise dos sentidos dos discursos de seis professoras iniciantes sobre seu trabalho e a gestão escolar na relação com a pertença profissional. Aplicou-se a abordagem analítica dos movimentos de sentido, estudo, entrevistas, adentrando em um contexto, para entendê-lo em suas relações e analisar como se produzem os discursos e os sentidos. Os discursos enfatizaram o esforço coletivo como um dos elementos de relação entre as categorias estudadas e para uma gestão escolar democrática. Há uma necessidade de articulação entre os sujeitos que implica em conhecer e reconhecer o outro e seu trabalho, dialogar e estabelecer parcerias.
\end{abstract}

Palavras-chave: Trabalho dos professores. Gestão escolar. Pertença profissional.

\section{ABSTRACT}

The analysis of the meanings of the discourses of six beginning teachers on their work and school management in the relation with professional membership is systematized. The analytical approach of the movements of meaning, study, interviews, was applied, entering into a context, to understand it in its relations and to analyze how the discourses and the senses are produced. The discourses emphasized the collective effort as one of the elements of relationship between the categories studied and for a democratic school management. There is a need for articulation between the subjects that implies knowing and recognizing the other and their work, dialoguing and establishing partnerships.

Keywords: Teachers work. School management. Professional membership.

\section{RESUMEN}

Se sistematiza el análisis de los sentidos de los discursos de seis profesoras principiantes sobre su trabajo y la gestión escolar en la relación con la pertenencia profesional. Se aplicó el enfoque analítico de los movimientos de sentido, estudio, entrevistas, adentrando en un contexto, para entenderlo en sus relaciones y analizar cómo se producen los discursos y los sentidos. Los discursos enfatizaron el esfuerzo colectivo como uno de los elementos de relación entre las categorías estudiadas y para una gestión escolar democrática. Hay una necesidad de articulación entre los sujetos que implica en conocer y reconocer el otro y su trabajo, dialogar y establecer alianzas.

Palabras clave: Trabajo de los profesores. Gestión escolar. Pertenencia profesional.

\section{INTRODUÇÃO}

\footnotetext{
${ }^{1}$ Pedagoga; Mestre em Educação pelo Programa de Pós-graduação em Educação da Universidade Federal de Santa Maria; Professora da rede pública do município de Santa Maria.imachry@yahoo.com.br.

2 Doutora em Educação; professora do Programa de Pós-graduação em Educação da Universidade Federal de Santa Maria. anaililferreira@yahoo.com.br.
} 
Nos estudos sobre educação escolar, considera-se o trabalho dos professores como elemento central, pois, ao analisar os contextos em que esses sujeitos produzem e estão inseridos, acaba-se por compreender como o sistema de gestão educacional e escolar se organiza e como se dão as relações de trabalho e emprego. Entende-se que trabalho e emprego são diferentes, porém se imbricam. $\mathrm{O}$ trabalho é a produção humana e o emprego é a alocação desse trabalho, regulada por aspectos burocráticos e legais. Diante desses pressupostos, este artigo objetiva sistematizar a Análise dos Movimentos dos Sentidos (AMS) dos discursos ${ }^{3}$ de professoras iniciantes sobre seu trabalho e a gestão escolar na relação com a sua pertença profissional ${ }^{4}$. Com base nessa problematização, surgem outras possiblidades de entendimento sobre o trabalho dos professores em relação com a gestão, já que estes sujeitos, se entende, são gestores do pedagógico:

\begin{abstract}
É nesse contexto pedagógico, uma vez esclarecido, que se insere o trabalho dos professores: a gestão do pedagógico, que acontece em todos os níveis da escola, mas, cabe, em primeira instância, aos professores realizá-la, pois o objetivo central da gestão do pedagógico é a produção do conhecimento e esta acontece na aula. Então, pensar a gestão do pedagógico tendo os professores como sujeitos significa mudança de compreensão da organização escolar. Consequentemente, haverá mudanças entre os lugares que os sujeitos ocupam no universo escolar; eliminando centralidades hierárquicas, concentração de decisões e fazendo a linguagem circular. (FERREIRA, 2008, p. 187).
\end{abstract}

Para assim o serem, os sujeitos necessitam se perceberem pertencentes ao contexto por meio do trabalho e do reconhecimento advindo do que produzem, ou seja, há demandas de se sentirem em condições de pertença profissional.

Então, são sistematizados nesse artigo argumentos provenientes de investigação realizada (que será descrita na seção a seguir), que tem como centralidade as relações entre o trabalho dos professores, a gestão escolar e a pertença profissional. Nessa perspectiva, os argumentos são apresentados em quatro seções que incluem, além da descrição dos aportes teórico-metodológicos, as concepções teóricas que orientaram a investigação e, por fim, considerações finais elaboradas a partir da análise dos dados produzidos durante a pesquisa.

\title{
ASPECTOS TEÓRICO-METODOLÓGICOS DA PESQUISA QUE DEU ORIGEM A ESTE ARTIGO
}

Ao realizar-se uma investigação tem-se a possiblidade de avanços na compreensão dos fenômenos. Através de um planejamento que inclui uma descrição dos aspectos teórico-metodológicos

\footnotetext{
${ }^{3}$ A Análise dos Movimentos de Sentidos é uma técnica aplicada no estudo dos sentidos em suas variações, incidências, repetições, faltas e exageros, etc, em suma, em seus movimentos. Metodologica e teoricamente, caracteriza-se como um estudo de linguagem, realizado com base em organização, reorganização, comparação, cotejamento e sistematização dos discursos, imbricando interpretação, análise, compreensão. (FERREIRA, 2020) ${ }^{4}$ A expressão "pertença profissional" é aplicada com o sentido que the foi conferido por Amaral (2010; 2016), como possibilidade de os sujeitos descreverem sua condição de trabalhadores e de trabalho: "a pertença à profissão se processa no âmbito de mediações, não podendo ser entendida a priori, mas a partir das relações de trabalho em um contexto sócio-histórico determinado. A pertença profissional [no caso dos professores] se refere a um viés político da docência já que concebe que os professores se percebem pertencentes ao contexto por meio do trabalho e do reconhecimento social através dele na coletividade". (AMARAL, 2016, p. 27).
} 
é possível o delineamento de limites, focalizar-se na problematização e a elaboração de estratégias para que os objetivos sejam atendidos. Esse planejamento também permite que, quando socializada a pesquisa, aqueles que acessam os resultados possam entender os caminhos de pesquisa percorridos.

Reitera-se que o estudo foi realizado com o propósito de avançar na compreensão do trabalho dos professores em suas relações com a gestão escolar e, nesse contexto, como descrevem a pertença profissional. Isso sem desconsiderar que, como alertam Strauss \& Corbin, "[...] o que descobrimos quando fizemos pesquisa é exatamente o quanto o mundo é complexo. Quando respondemos a algumas perguntas, formulamos outras" (2008, p. 63). Nesse sentido, pesquisar é uma ação contínua e constante, implicada no processo humano de necessitar sempre conhecer mais e melhor.

Por se tratarem de fenômenos humanos e sociais, optou-se por uma abordagem qualitativa, característica de estudos no campo educacional. Tal abordagem mantém os critérios de cientificidade na escolha de técnicas e métodos específicos, entretanto, com o diferencial no tratamento dos dados, já que permite perceber e analisar os discursos dos sujeitos, em suas relações, considerando a complexidade do contexto e a não neutralidade.

Nesse viés, a pesquisa que deu origem a este artigo caracteriza-se por ser um estudo ${ }^{5}$ realizado com seis professoras iniciantes ${ }^{6}$, que trabalham em escolas públicas de Santa Maria. São mulheres, entre 25 e 50 anos, graduadas em Pedagogia, que trabalham nos anos iniciais do Ensino Fundamental. O contexto de análise dos discursos foi a escola. Os sujeitos, interlocutoras da pesquisa, são professoras iniciantes que, ao se inserirem no mundo do trabalho, elaboraram sentidos de pertença profissional, relacionados à gestão escolar com a qual passaram a se implicar. Escolheuse entrevistar professoras que trabalham a menos de dois anos em alguma das escolas da Rede Municipal de Santa Maria, no Rio Grande do Sul, pois a pertença profissional se constitui em cada realidade específica marcada pelo processo de inserção no trabalho. Do mesmo modo, reitera-se que se escolheu o contexto de uma rede pública de educação, corroborando o comprometimento que se tem com este sistema que proporciona educação escolar para a maior parte da população, além de serem as professoras entrevistadas e as escolas onde trabalham regidas pelas mesmas determinações legais. Tal delimitação caracteriza um estudo por sua especificidade, pois os sentidos são analisados se em relação a esse contexto e a esses sujeitos. Porém, sendo esses sujeitos representantes de um grupo maior de sujeitos, o de professoras iniciantes no trabalho na rede pública, apresentam seus resultados critérios de universalização possível: o que pensam as mulheres? Como se sentem em relação à sua pertença profissional? Como relacionam seu trabalho, a gestão escolar e a pertença profissional?

\footnotetext{
${ }^{5}$ Diferencia-se pesquisa e estudo. Aquela diz respeito somente à produção e análise de dados. O estudo, pelo que se entende, inclui a pesquisa e vai além, analisando não somente os dados produzidos, mas as condições de produção, os sujeitos interlocutores e as produções de outros autores, na comunidade acadêmica. (FERREIRA, 2017; 2020)

${ }^{6}$ As professoras foram denominadas com designações para flores: Margarida, Rosa, Violeta, Dália, Íris e Gardênia. Desse modo, objetivou-se preservar suas identidades.
} 
Quanto à perspectiva teórica e procedimental, aplicou-se a Análise dos Movimentos de Sentidos. Configura-se em uma abordagem teórica desenvolvida no grupo de pesquisa ${ }^{7}$ em que se trabalha, aplicada no estudo dos discursos. Os discursos são materialidades cujas contradições, movimentos, sentidos, em suas contradições, contextos, historicidades, indicam características que são sintetizadas sob a forma de categorias. Os discursos são, então, evidências materiais dos sujeitos, e como tal, ao serem analisados, na condição de dados produzidos, podem permitir a análise dos fenômenos que são problematizados pelos pesquisadores. Isto porque, se o sujeito produziu o discurso, este vem no lugar dele, é significado por ele, indica o que ele produziu (FERREIRA, 2020).

Quanto ao procedimento, o estudo permitiu adentrar em um contexto espaço-temporal, para entendê-lo em suas relações e analisar como se produzem os discursos e os sentidos pelos sujeitos. Entende-se também a Análise dos Movimentos de Sentidos como um modo de pesquisar, no qual os sujeitos pesquisadores atribuem sentidos ao real e, ao fazê-lo, criam condições de transformá-lo. Como técnica de produção de dados foram realizadas entrevistas semiestruturadas (FERREIRA, 2020). A elaboração do percurso metodológico que deu origem a este artigo incluiu:

1) entrevista semiestruturada com as seis professoras iniciantes. A técnica de produção de dados através da entrevista permitiu a interação com as professoras em seus ambientes de trabalho. A entrevista orientou-se porque questões que focalizaram a problematização que deu origem ao estudo, dividas em três eixos: a) com relação ao qual era o trabalho que realizavam como professoras? b) se percebiam-se trabalhadoras, descreviam sua pertença profissional? c) como descreviam a relação entre a gestão escolar e seu trabalho.

2) análise dos dados produzidos. A análise dos discursos das professoras considerou a recorrência das categorias, os movimentos de sentidos, a comparação descritiva entre estes sentidos, de modo sistemático, por meio da elaboração de tabelas. Partiu-se de como as professoras se descreviam como trabalhadoras e como descreviam seu trabalho, para, então, conhecendo quem produz o discurso, atribuir sentidos. Nesse afã, transcreveram-se os discursos, subdividiu-se em tabelas, organizando por categorias. Foram comparadas as categorias dentro do discurso de cada interlocutora verticalmente e nas recorrências nos demais discursos, horizontalmente. Considerou-se a aproximação semântica e a frequência das categorias. Isso quer dizer que não foi levada em consideração apenas determinada palavra, mas todas que pudessem ser representadas por ela, devido ao sentido. Sob esse critério, foi possível perceber as dimensões e elementos constitutivos das categorias no entendimento dos professores e, então, a importância atribuída pela ênfase expressa na repetição, não somente de determinados vocábulos como de outros semanticamente relacionados. Assim, cada categoria foi estudada e analisada particularmente e em sua relação com o todo do discurso individual e o todo dos discursos de todas a interlocutoras. A partir desse trabalho, foi possível estabelecer alguns sentidos como indicativos do trabalho das professoras na relação com gestão escolar e a pertença profissional.

3) reanálise e sistematização dos dados sob a forma deste artigo. A sistematização consiste em produzir conhecimento sobre o fenômeno estudado. É quando se transforma em linguagem tudo

\footnotetext{
${ }^{7}$ Kairós - Grupo de Estudos e Pesquisas sobre Trabalho, Educação e Políticas Educacionais/UFSM.
} 
que analisou (FERREIRA, 2020). No caso específico desse estudo, foi quando se conheceu os sentidos problematizados nos discursos das professoras.

Essa aporte teórico-metodológico orientou o estudo e foi sistematicamente organizado para se entender os sentidos atribuídos pelas professoras ao seu trabalho em relação à gestão escolar e à pertença profissional. Na seção seguinte passar-se-á a descrever as categorias com as quais se trabalhou no estudo.

\section{TRABALHO DOS PROFESSORES E GESTÃO ESCOLAR}

O trabalho dos professores inclui as vivências e a produção na escola e, por isso, entende-se que é assim que ocorre a elaboração da pertença profissional, a partir da inserção no trabalho escolar. Assim, ao realizarem seu trabalho, os professores se constituem trabalhadores. E o seu trabalho, defende-se, é a gestão do pedagógico, inclui a produção da aula, a elaboração de um projeto pedagógico inicialmente individual, mas em conexão com os demais sujeitos da escola, configurandose em projeto pedagógico da instituição. Por isso, o entendimento de os professores serem gestores compõe-se a partir de dois aspectos principais que implicam na gestão escolar: primeiramente, pela gestão do pedagógico e pela participação nos processos de gestão, como na elaboração do projeto pedagógico escolar e nas demais decisões que acabam por caracterizar a escola e seu modo de gestão. Então, ao realizarem seu trabalho como professores gestores do pedagógico (FERREIRA, 2017), esses sujeitos vivenciam a gestão escolar, o que Ihe propicia condições para a elaboração da sua pertença profissional. Esses argumentos se evidenciaram nas entrevistas. Os discursos das interlocutoras indicaram sentidos sobre o trabalho que realizam: "Meu trabalho é fundamentado por uma metodologia que escolhi e através dela realizo minhas aulas" (PROFESSORA ROSA). Observouse na comparação de sentidos que transitam do individual para o coletivo: "Meu trabalho se refere a um conjunto de decisões e ações relativas às técnicas e metodologias que são adotadas na escola para a realização do trabalho educativo" (PROFESSORA DÁLIA).

Dois desafios principais foram propulsores para a inserção da expressão "gestão escolar" no sistema educacional. Até a década de 1990, para se referir ao modo de organizar este sistema, adotava-se a expressão "administração educacional", o que frequentemente gerava o entendimento de que os aspectos pedagógicos e administrativos da educação seriam tratados separadamente. segundo fator foi a expansão do sistema público de educação e, em decorrência, a necessidade de mais vagas para atender a demanda, que exigiram repensar a organização e o modo de coordenar os esforços nas diferentes esferas do sistema educacional. Essa associação entre a expansão do sistema público de educação e a mudança de "administração educacional" para "gestão educacional", segundo Luce \& Medeiros, pode ser assim apresentada:

O principal debate sobre a gestão escolar toma vulto a partir de 1970 , quando a luta da classe trabalhadora pelo direito de seus filhos à escola pública impõe a reflexão sobre os motivos da falta de vagas, das altas taxas de reprovação e do consequente abandono escolar, assim como das condições precárias nas instalações escolares e da limitada profissionalização do magistério. (2006, p. 15). 
Essas manifestações impactaram as políticas educacionais brasileiras. $E$ foram além, pois não se queria apenas gestão educacional, mas gestão educacional democrática. Resultante desse no texto da Constituição Federal do Brasil, de 1988, a gestão democrática é apresentada como princípio para educação pública no país.

O inédito princípio da gestão democrática da educação é uma importante conquista da Constituição de 1988, ainda que seja difícil avaliar o quanto representou na prática da gestão escolar por todo o país. No processo constituinte este foi um tema polêmico, que opôs duas posições principais: a primeira, defendida pelo Fórum Nacional em Defesa da Escola Pública, afirmava o princípio da gestão democrática com a participação de toda a comunidade escolar (funcionários, docentes, e estudantes); a segunda, encabeçada pelos privatistas, tentou limitar de diversos modos essa participação, tanto na forma de composição de seus membros quanto na qualidade de sua intervenção efetiva. No texto final, a Constituição foi duplamente restritiva: excluiu o setor privado da necessidade de se adequar ao referido princípio e também postergou para legislação complementar a definição do que seria a gestão democrática. (MINTO, 2010, p.182).

Em todo o caso, o princípio estava lançado e, como tal, era inovador, em um contexto de centralização das decisões na figura de um diretor escolar, em muitos contextos, determinado e empossado por decisão política, passando a atender às normativas que the chegavam regionalmente pela Delegacia de Educação (denominação das atuais Coordenadorias de Educação, no Rio Grande do Sul).

Influenciando as demais políticas, esse princípio constitucional foi evidenciado na LDB 9.394/96, que ainda vigora, no inciso VIII, do artigo $3^{\circ}$, ao estabelecer: "gestão democrática do ensino público, na forma desta Lei e da legislação dos sistemas de ensino". Importante ressaltar que há compreensões diferenciadas de gestão democrática. Há até mesmo referências à administração escolar que são denominadas de gestão escolar democrática e, no entanto, não evidenciam estar amparadas em princípios democráticos, ou porque são demasiadamente centralizadas e não envolvem todos os sujeitos da comunidade escolar; ou porque pregam a participação, mas a organização da escola não considera os resultados dessa participação dos sujeitos da comunidade. Isto posto, cabe ponderar:

[...] a participação democrática não se dá espontaneamente, sendo antes um processo histórico em construção coletiva coloca-se a necessidade de se preverem mecanismos institucionais que não apenas viabilizem, mas também incentivem práticas participativas dentro da escola pública. (PARO, 1986, p. 46).

E participação e gestão educacional se imbricam, não havendo esta sem aquela:

[...] o entendimento do conceito de gestão já pressupõe, em si, a idéia de participação, isto é, do trabalho associado de pessoas analisando situações, decidindo sobre seu encaminhamento e agindo sobre elas em conjunto. Isso porque o êxito de uma organização depende da ação construtiva conjunta de seus componentes, pelo trabalho associado, mediante reciprocidade que cria um todo orientado por uma vontade coletiva. (LÜCK, 1996, p. 37).

Luce \& Medeiros argumentam sobre a necessidade de se estar atento aos discursos sobre gestão democrática, porque estes exigem reflexão, entendimento e implementação. Nesse sentido, as autoras defendem ser a democracia um aperfeiçoamento da vida humana que reconhece e lida com diferenças oriundas da convivência, dos modos de participação e implicação de cada sujeito. Isso faz com que os princípios democráticos na gestão escolar para serem sólidos necessitem de uma base 
conceitual que os amparem. Por isso, cabe descrever e enfatizar o que se entende por gestão democrática, e como tal, emancipadora, no ambiente escolar:

[...] um processo de aprendizado e de luta política que não circunscreve aos limites da prática educativa, mas vislumbra, nas especificidades dessa prática social e de sua relativa autonomia, a possibilidade de criação de canais de efetiva participação e de aprendizado do "jogo" democrático e, consequentemente, do repensar das estruturas de poder autoritário que permeiam as relações sociais e, no seio dessas, as práticas educativas. (DOURADO, 2011, p. 96).

Importante considerar esse argumento de Dourado, porque a mudança de "administração escolar" para "gestão escolar" (assentada em princípios democráticos) não se configura em apenas substituição. Implica superação. Ainda que o conceito de gestão tenha como base o de administração, aquele apresenta uma concepção mais ampliada, pois maior comprometimento, participação e ação.

A organização e articulação provenientes de como acontece a gestão escolar estão diretamente relacionadas com a qualidade da educação. A gestão educacional e, principalmente, democrática, é um modo de mobilizar para "[...] sustentar e dinamizar o modo de ser e fazer dos sistemas de ensino e das escolas, para realizar ações conjuntas, associadas e articulada, visando ao objetivo comum da qualidade de ensino e os seus resultados" (LÜCK, 2006, p. 25).

$\mathrm{Na}$ escola, especificamente, âmbito micro onde acontece o trabalho dos professores, a gestão implica mobilização do modo de ser e fazer acontecer as políticas educacionais, amalgamadas com as características culturais, sociais, políticas e, portanto, pedagógicas da instituição. Somente em um espaço e tempo assim caracterizados os professores serão gestores do pedagógico, participando e contribuindo com seu trabalho realizado em acordo com os princípios democráticos que organizam a escola.

\section{A PERTENÇA PROFISSIONAL COMO RELAÇÃO ENTRE O TRABALHO DOS PROFESSORES E A GESTÃO ESCOLAR}

A análise dos discursos permitiu que se compreendesse o entendimento das professoras, interlocutoras da pesquisa, acerca das categorias trabalho, gestão escolar e pertença profissional:

I) Quanto à categoria trabalho, os sentidos encontrados nos discursos centralizaram-se na relação com os estudantes, uma vez que são eles a razão imediata do trabalho realizado, afirmaram as professoras. A sala de aula como o espaço e tempo do trabalho também foi bastante evidenciada. Ou seja, são as interações que dão sentido à sala de aula onde é realizado o trabalho, para as professoras.

II) Sobre gestão escolar, ficou evidente a ênfase no grupo e no trabalho coletivo realizado: "A participação é fundamental para a democratização dos processos de gestão" (PROFESSORA VIOLETA).

III) A pertença profissional pode ser dividida em quatro perspectivas: com relação aos estudantes: "Trabalho com estudantes, de modo intencional e sistematizado, objetivando que conheçam (PROFESSORA MARGARIDA)"; com relação à direção da escola: "Vivi momentos em que o responsável por liderar o processo de gestão apontou 
situações desagradáveis que me prejudicaram em meu trabalho" (PROFESSORA ROSA); com relação a toda a escola; e com relação a si próprio. Dessas, a que mais influencia na pertença profissional, segundo as professoras, é a direção da escola, o que demonstra ainda uma relação hierárquica bastante arraigada em relação a como se organiza a escola: se a direção não valida, valoriza ou menciona, o trabalho dos professores e os próprios professores não se sentem confortáveis.

De modo geral, os sentidos evidenciaram que as professoras, em seus discursos, interrelacionam trabalho, gestão escolar e pertença profissional. Argumentam que tudo depende do modelo de gestão aplicado na escola. Seus discursos levam a perceber que a gestão educacional ainda é um tema em discussão e em processo de democratização nas escolas: "Ainda não temos uma escola democrática. Por exemplo, as reuniões são um mecanismo, uma espécie de álibi, para impor uma decisão" (PROFESSORA ÍRIS). Também a Professora Gardênia relatou sobre as reuniões: "Aí ela [a diretora] falou 'vai ser decidido isso, isso e isso'. Isso não é gestão". E destaca-se ainda outro relato: "São realizadas reuniões sobre assuntos já decididos pelo Ministério da Educação. Essas são para nos comunicar e pronto" (PROFESSORA ÍRIS). Em outra escola, as reuniões são assim descritas: "Houve reuniões para planejamento de atividades para data comemorativa e reuniões para elaboração do Projeto Pedagógico da escola. Mas não houve reuniões para conversarmos sobre o que estamos trabalhando em aula" (PROFESSORA ROSA). Nota-se que as questões pedagógicas e administrativas são abordadas nas reuniões, porém não o são como gostariam as professoras. Essas parecem apelar para uma centralidade maior naquilo que produzem como professoras. Desse modo, o modelo de gestão aliado ao seu trabalho, promovendo-o e amparando-o, pode dar-lhes condições de serem gestores não somente do pedagógico, mas da escola como partícipes nas decisões, ações e processos.

Ainda sobre a categoria gestão, observou-se uma recorrência: as professoras associaram o termo gestão à organização: "A gestão da escola indica como deve ser organizado nosso tempo, nossas aulas, nossa relação com os estudantes" (PROFESSORA VIOLETA). Para tanto, há uma organização tanto dos aspectos burocráticos, quanto dos aspectos pessoais e são estabelecidas rotinas organizacionais, espaços sócio-organizacionais que regulam as relações entre os sujeitos.

Como evidência de democratização da gestão, foi citada uma ocorrência na qual todos os setores da comunidade se envolveram na tentativa de solucionar um problema:

\footnotetext{
Houve uma situação bem complicada. Tratou-se de indisciplina em sala de aula. A diretora, a coordenadora e a orientadora estava sempre me ajudando, procurando tirar o estudante da sala, resolver certas questões com a família. Os colegas professores me apresentavam sugestões, tentamos tudo. Mas chegou a um ponto em que a Direção convidou o estudante a se retirar da escola, porque não era mais possível lidar com a situação. (PROFESSORA GARDÊNIA).
}

Nessa situação, houve mobilização de professores, pais, equipe da gestão. Entretanto, não foram bem-sucedidos, e foi necessário desistir. A Professora denotou ter se percebido acolhida na dificuldade, mas fracassada por não chegar a um bom termo, quais sejam: superar as dificuldades de interação do estudante com a turma e a conclusão do ano letivo. 
Assim, a dificuldade para uma gestão democrática na escola é compreensível em uma sociedade como a atual, com pouca vivência de democratização no social ampliado, quanto mais no espaço escolar. Todavia, não se justificam mecanismos de controle e atitudes antidemocrática que fragilizam os professores e afetam seu trabalho. A Professora Rosa pôs em relevo a importância atribuída ao trabalho em grupo, pois entre colegas professores é difícil acontecer: "A gente vê que falta essa parte no processo de gestão. Os professores não se organizam. Organização zero. Recebe-se muitas ordens da gestão, cada um faz o que quer, ninguém estende a mão e trabalha solidariamente". E outra professora, concordando sobre a importância do trabalho coletivo, destacou: "[...] gestão escolar é o coletivo, é a condição de todos se verem participando, inclusive os estudantes" (PROFESSORA VIOLETA). Para esta professora, "ninguém faz nada sozinho". Pensa-se estar aqui uma questão fundamental para a pertença profissional. Não é possível narrar que há uma gestão escolar democrática e continuar a perceber-se agindo individualmente, atendendo somente a seus interesses, sem partilha, sem convívio e socialização.

O sentido de pertencimento à profissão, ao conjunto de professores, ao trabalho que esse conjunto profissional realiza, elaborado no início da carreira continua se transformando, assim como o processo de gestão será sempre elemento interveniente no trabalho dos professores. E, no momento em que outros professores iniciam em sua condição de trabalhadores, adentrando na profissão, aqueles que já estão na escola, assim como os professores que estão na condição de gestores, marcam, educam, a partir de como encaminham o processo de inserção.

Relataram as interlocutoras, que ao chegarem à escola, se viram diante de uma nova e desafiadora realidade. Surgiram desafios com os quais tiveram que se haver: "Faltava-me experiência. Foi meu primeiro trabalho" (PROFESSORA DÁLIA). Há também a questão da integração ao grupo de novos colegas professores: "Eu ia trabalhar na alfabetização, sentia-me observada, vigiada pelas colegas alfabetizadoras que estavam lá há anos. Era desconfortável. Com o tempo, passaram a me respeitar" (PROFESSORA ÍRIS). De qualquer forma, na chegada à escola, já é possível encontrar alguns desafios e o ponto principal diz respeito a afirmar-se pelo trabalho: "Eu tive uma reunião de recepção, mas o trabalho em sala de aula me tirava o sono" (PROFESSORA MARGARIDA).

De acordo com a análise dos discursos, pode-se argumentar que, apesar da vivência, das experiências, ou da falta de experiências, as professoras, ao chegarem na escola onde trabalham atualmente, encontraram desafios diferenciados e necessitaram agir para elaborar um sentido, para si, de pertença profissional ao realizarem seu trabalho nesses contextos de gestão escolar ora vivenciados. Para a Professora Margarida, apenas uma colega foi capaz de contribuir para sua pertença. Para a Professora Dália, houve um grupo de colegas, que trabalhavam no mesmo turno. As Professoras Gardênia e Íris não contaram com ajuda, mas a simples aceitação de sua presença naquele momento, naquela escola, ajudou a vencer as barreiras do desconhecido, impulsionando a um trabalho em zona de conforto. A Professora Violeta somente sentiu algo à semelhança de pertença profissional, quando obteve o reconhecimento das famílias, no final do ano, pelo trabalho que desenvolveu na turma. A Professora Rosa se sentiu pertencendo profissionalmente à escola desde a época de graduação, pois realizou estágios e atividades extracurriculares naquele local e foi bem acolhida. Elaborar sentidos de pertença profissional é complexo, particular e, ao mesmo tempo, 
coletivo. Esses sentidos não possuem necessariamente meio e fim. Renovam-se cotidianamente. Pode-se até indicar seu início, mas continuam presentes nas relações e no trabalho, sendo constantemente transformados.

Para indicar este processo de transformação e elaboração da pertença profissional também foram analisadas as dicotomias presentes nos discursos, que demonstraram polos opostos de sentidos na percepção das professoras, elaborados frente às vivências e reflexões durante o seu trabalho cotidiano na escola. Ficou translúcida a capacidade de os sujeitos perceberem certas relações, por vezes opostas, permeando suas vivências, em meio à realidade em sua complexidade. Demonstra, do mesmo modo, que o trabalho dos professores na escola possui múltiplas faces, pode ser muito tranquilo e prazeroso, mas pode, do mesmo modo, passar por momentos de dificuldades e desafios. Por exemplo, foi narrado pela Professora Rosa que a gestão da escola queria discutir aspectos corriqueiros como atividades que marcassem datas comemorativas. O grupo de professores dividiu-se: uns apoiaram e outros criticaram. Relata a Professora: "Senti-me desintegrada, pois minhas amigas ficaram no grupo de apoio e eu no de crítica. Pensei que teria que começar do início meu processo de integração, senti-me rejeitada por elas. Com o tempo passou (PROFESSORA ROSA). Esse é um exemplo das dicotomias que perpassam o trabalho dos professores, elementos presentes nas relações humanas e, portanto, no trabalho dos professores.

Então, estando no contexto da gestão escolar, como trabalhadoras, gestoras do pedagógico, realizando seu trabalho, cada professora, em meio a esse contexto, produz o seu processo de pertença profissional, e este está no nível da gestão escolar e, ao mesmo tempo, no nível de como os professores se sentem reconhecidos pelo trabalho que realizam.

\section{CONSIDERAÇÕES FINAIS}

Nesse artigo, foram apresentadas constatações geradas a partir do estudo e análise dos discursos de seis professoras iniciantes na rede pública municipal de Santa Maria/RS acerca do trabalho que realizam e como o relacionam com a gestão escolar e a pertença profissional.

Tanto a análise dos discursos quanto o estudo bibliográfico foram essenciais para dar consistência à elaboração teórica oriunda da investigação. Na relação com os referencias e com as interlocutoras, os dados se produziram, condicionados pela subjetividade e o momento histórico-social que vivenciavam os sujeitos. Desse modo, são dados particulares e únicos que afirmam sua relevância justamente pelas inferências que permitem, quando lidos e analisados em uma perspectiva contextual.

De acordo com os discursos analisados pode-se perceber ainda arraigada a compreensão de gestão escolar centralizada na direção da escola, o que indica a necessidade de processos democráticos mais efetivos, possibilitando aos professores assumirem seus lugares como gestores do pedagógico em uma perspectiva mais coletiva, que transcenda ao espaço e tempo da sala de aula. $\mathrm{O}$ desafio continua a ser o de superar a separação entre os processos administrativos e os pedagógicos, tratados, em momentos diferentes do cotidiano escolar e, geralmente, sem relação entre si.

As dificuldades para uma gestão democrática, passados vinte e três anos da publicação da LDB 9.394/96 ainda são evidentes, mesmo que muitos trabalhem e lutem por isso. Nesse processo, é 
no trabalho conjunto que se encontram forças e possibilidades para ir adiante, pois, segundo os discursos das interlocutoras, não realizar nada sozinho não é apenas uma questão de querer e sim uma possibilidade diante de tantas dificuldades e demandas cotidianas no trabalho escolar.

Assim como a gestão escolar e o trabalho, a pertença profissional necessita de esforço coletivo. Este é um dos elementos de relação entre as categorias estudadas e o ponto central para uma gestão escolar democrática. As professoras entrevistadas evidenciaram em seus discursos a importância do reconhecimento e acolhida no coletivo durante e após a inserção na escola. Há uma necessidade de articulação entre os sujeitos que implica em conhecer e reconhecer o outro e seu trabalho, dialogar e estabelecer parcerias.

As professoras relataram encontrar desafios diferentes que exigiram atitudes diferentes e a necessidade de manter essas atitudes em todos os dias de trabalho. Isso porque como a elaboração do sentido de pertença profissional se dá nas relações humanas, no e pelo trabalho, no contexto da gestão escolar e em relação com ela, está em transformação, exigindo dos sujeitos um trabalho coletivo, intencional e sistematizado. E este trabalho precisa ser apreendido, pois não é tão simples e precisa considerar que as pessoas se transformam também, gerando recomeços a cada momento. Assim, o cerne das relações entre gestão escolar e trabalho dos professores está na pertença profissional, sendo este um ponto de referência para próximos estudos.

\section{REFERÊNCIAS}

1. AMARAL, C. L. C. "À procura de pertença profissional: as interfaces do trabalho nos discursos de egressos(as) do curso de Letras - Inglês da Universidade Federal de Santa Maria". Dissertação de Mestrado. Programa de Pós-graduação em Educação. Universidade Federal de Santa Maria, 2010.

2. AMARAL, C. L. C. "Pertença profissional, trabalho e sindicalização de professores: mediações e contradições nos movimentos do capital". Tese de Doutorado. Programa de Pós-graduação em Educação. Universidade Federal de Santa Maria, 2016.

3. BRASIL. Lei $n^{\circ}$ 9.394, de 20 de dezembro de 1996. Estabelece as diretrizes e bases da Educação Nacional. In: Diário Oficial da União, ano CXXXIV, n²4, 23 de dezembro de 1996.

4. DOURADO, L. F. "A escolha de dirigentes escolares: políticas e gestão da educação no Brasil". IN: FERREIRA, N.S.C. Gestão democrática da educação: atuais tendências, novos desafios. 7 ed. São Paulo: Cortez,2011.

5. FERREIRA, L. S. "Gestão do Pedagógico: de qual pedagógico se fala?". In: Currículo sem Fronteiras, v. 08, n. 02, pp. 176-189, jul-dez 2008. 
6. FERREIRA, L. S. Trabalho pedagógico na escola: sujeitos, tempo e conhecimentos. Curitiba: Editora CRV, 2017.

7. FERREIRA, L. S. "Discursos em análise na pesquisa em educação: concepções e materialidades". In: Revista Brasileira de Educação, v. 25, pp. 1-18, 2020.

8. LUCE, M. B; MEDEIROS, I. L. P. Gestão escolar democrática: concepções e vivências. Porto Alegre: Editora da UFRGS, 2006.

9. LÜCK, H. Concepções e processos democráticos da gestão educacional. Petrópolis, RJ: Editora Vozes, 2006.

10. MINTO, L. W. "A administração escolar no Contexto da Nova República e do Neoliberalismo". IN: ANDREOTTI, A; LOMBARDI, J. C.; MINTO, L. W. História da Administração escolar no Brasil. Campinas, SP: Editora Alínea, 2010. pp. 173 - 199.

11. PARO, V. H. Administração escolar: introdução crítica. São Paulo: Cortez, 1986.

12. STRAUSS, A; CORBIN, J. Pesquisa qualitativa: técnicas e procedimentos para o desenvolvimento de uma teoria fundamentada. Porto Alegre: Artmed, 2008.

\section{Liliana Soares Ferreira}

Professora do Programa de Pós-graduação em Educação da UFSM.

\section{Isabel Daiane Weber Machry Rodrigues}

Pedagoga, Mestre em Educação PPGE/UFSM. Professora da Rede Municipal de Educação de Santa Maria/RS.

Como citar este documento:

FERREIRA, Liliana Soares; WEBER MACHRY RODRIGUES, Isabel Daiane. Gestão escolar e pertença profissional: uma análise dos discursos de professoras iniciantes. Reflexão e Ação, Santa Cruz do Sul, v. 28, n. 2, jun. 2020. ISSN 1982-9949. Disponível em: $<$ https://online.unisc.br/seer/index.php/reflex/article/view/13058>. Acesso em: doi:https://doi.org/10.17058/rea.v28i2.13058. 